\title{
Up-regulation of Nucleophosmin 1 in Cisplatin-induced Death of Mouse Osteoblastic MC3T3-E1 Cells
}

\author{
Myung Hee Kim, ${ }^{\neq} \neq$Su-Ui Lee, ${ }^{+, \$}$ Yong Ki Min, and Seong Hwan Kim ${ }^{+*}$ \\ ${ }^{\dagger}$ Laboratory of Chemical Genomics, Korea Research Institute of Chemical Technologv, P. O. Bor 107, Daejeon 305-600, Korea \\ E-mail: hrancikrict.rekr \\ ¿Department of Biochemistr, "separtment of Biologv, Chungnam National Lniversity, Daejeon 305-764, Korea \\ Received November 30, 2007
}

Key Words : Cisplatin. Nucleophosmin 1. Osteoblast. Proteomics

Cisplatin (cis-diamminedichloroplatinum II. Fig. IA) is one of the most used chemotherapentic agents in the management of malignant bone and soft tissue tumors, but its treatment can show the impairment of bone formation. Actually. during the administration of cisplatin. its effect has been reported to be targeted directly on the proliferation and differentiation of bone-forming cells. ${ }^{1}$ In addition. in the study to elucidate the effect of cisplatin on regenerate bone formation during the distraction and consolidation phases of bone transport osteogenesis, cisplatin-treated dogs had decreased mineralized bone volume, decreased percentage of woven bone volume. decreased percentage of osteoblastcovered bone and increased porosity. suggesting that bone formation and resorption may be uncoupled in cisplatintreated regenerate bone. ${ }^{3}$

Throughout adult life. bone tissue is subject to a continuous process of turnover, whereby old bone is removed and replaced by new bone by the coupled processes of bone resorption and bone formation. Osteoblasts are the bone lining cells responsible for the production of the matrix constituents such as a collagen and originate from a bone marrow stromal stem cells under the influence of local growth factors. These precursors undergo proliferation and differentiate into preosteoblasts and then into mature osteoblasts. Interestingly, several studies have clearly shown the deleterious effect of cytotoxic chemotherapy on protein synthesis and DNA replication resulting in diminished bone fonmation. but the precise mechanism has not been studied yet. $^{3}$

Therefore, in this study. we evaluated the effect of cisplatin on the survival of osteoblasts and applied the proteomics technology for identifying protein(s) involved in the action of cisplatin in osteoblasts.

First. the effect of cisplatin on the proliferation of MC3T3El cells was evaluated (Fig. lB). In a dose-dependent manner. the proliferation of MC3T3-El cells was siguificantly inhibited $-90 \%$ and $-54 \%$ in 1-day and 4 -day culture by the treatment of $100 \mu \mathrm{M}$ cisplatin, respectively. Since $100 \mu \mathrm{M}$ of cisplatin significantly inlibited the proliferation of MC3T3-El cells in 1-day culture, cells incubated with/ without $100 \mu \mathrm{M}$ cisplatin for $\mathrm{l}$ day were used for identifying the differentially expressed protein(s). Using Phoretix 2D image analysis software. the altered spots were compared based on their volume percentages in the total spot volume over the whole gel images. Of over 500 protein spots resolved in a 2-DE gel with silver staining analyzed. 18 spots was above 2-fold increased, whereas 35 spots decreased in cisplatin-treated cells (data not shown). Among these spots, the circle-indicated spot in Figure 2A was increased 2.63fold in cisplatin-treated cells compared to control. The circle-indicated spot was digested in gel with trypsin and subjected to peptide mass fingerprinting (PMF). The representative MALDI-TOF MS spectrum for the spot was shown in Figure 2B. According to the PMF. the estimated pI and molecular weight (MW) by the 2-DE map, the circleindicated spot in Figure 2A was identified to nucleophosmin I (NPM, Fig. 2C).

Cisplatin-induced protein expression of NPM was confirmed using Western blot analysis (Fig. 3). NPM was induced by cisplatin in a dose-dependent manner and its actill-nonmalized expression levels in $100 \mu \mathrm{M}$ cisplatin was -2 -fold increased compared to control. which was similar with the result observed in 2-DE analysis. NPM is a nucleolar phosphoprotein and it appears to be a multi-func-
A

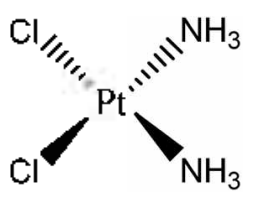

B

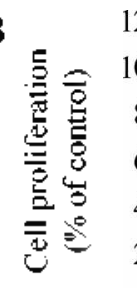

120

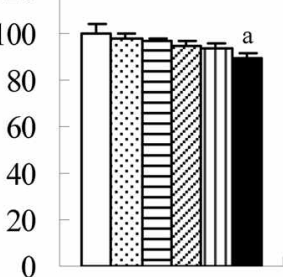

1-day



4-day

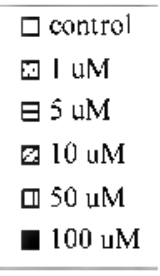

$\square$ control

I UM

日 $5 \mathrm{uM}$

$50 \mathrm{M}$

Figure 1. (A) Structure of cisplatin (B) The effect of cisplatin on the proliferation of MC 3T3-EI cells. Cell proliferation was measured as described in 'Materials and Methods', a, $P<0.01: b, P<0,001$. 
A



Spot intensity (relative to control)

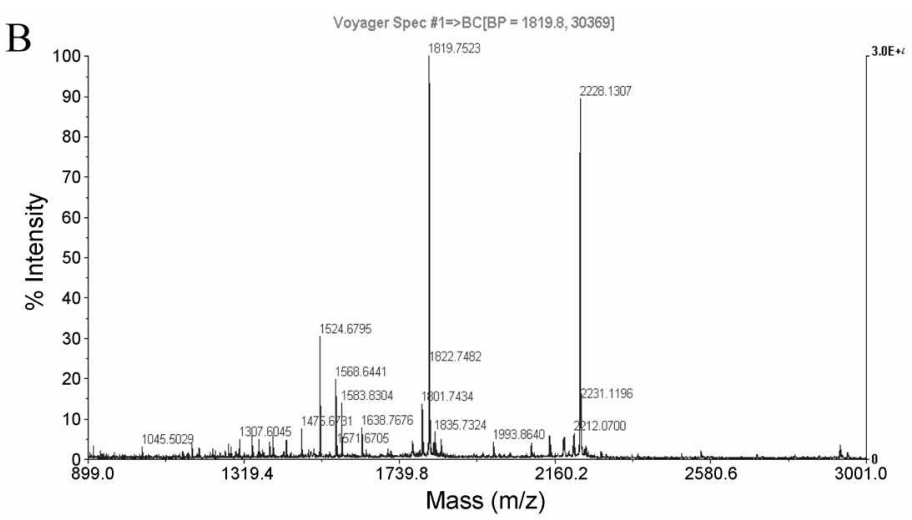

\begin{tabular}{ccccccc}
\hline Protein name & $\begin{array}{c}\text { Accession } \\
(\mathrm{GI})\end{array}$ & $\begin{array}{c}\text { No. of matched } \\
\text { peptides }\end{array}$ & $\begin{array}{c}\text { Sequence } \\
\text { coverage }(\%)\end{array}$ & $\begin{array}{c}\text { Theoretical } \\
\text { Mr(kDa)/pl }\end{array}$ & $\begin{array}{c}\text { Measured } \\
\text { Mr(kDa)/pl }\end{array}$ & Score \\
\hline Nucleophosmin 1 & 2500582 & 5 & 28 & $29.19 / 4.5$ & $40 / 4.6$ & $1.90^{\mathrm{a}} ; 73^{\mathrm{b}} ; 1.11 \mathrm{E}+04^{\mathrm{c}}$ \\
\hline
\end{tabular}

Figure 2. 2-DE analysis. (A) The partial 2-DE images were presented to show the differentially expressed protein (circle-indicated spot) in cisplatin-treated MC3T3-EI cells. The relative volume of circle-indicated spot was analyzed by Phoretix 2D software. (B) MALDI-TOFMS spectrum of the analysis of the peptide derived from the circle-indicated spot atter in-gel digestion. (C) Circle-indicated spot was identified as nucleophosmin 1 by using 2 score from ProFound ${ }^{\prime \prime}$, MOWSE score from MASCOT ${ }^{h}$ and MOWSE score from MS-fit ${ }^{c}$.

tional protein. Interestingly, the expression level of proliferating cellular nuclear antigen (PCNA) that is an essential coniponent for DNA repair machinery has been shown to be correlated with NPM expression in fibroblast. ${ }^{4}$ In addition. NPM has been recently reported to regulate the PCNA promoter. ${ }^{5}$ Therefore, we further examined the expression level of PCNA and found that it was also induced by cisplatin in a dose-dependent manner. These suggested that the up-regulation of NPM in cisplatin-treated osteoblasts might be part of a protective response to enhance DNA repair.

In addition. cisplatin-induced genotoxicity has been reported in several studies ${ }^{6}$ Considering that NPM has been identified as one of genotoxic stress-responsive RNA-binding proteins or chromatin-binding proteins in response to DNA double-strand breaks. ${ }^{7}$ cisplatin-induced genotoxic stress (or DNA damage) in osteoblasts might be regulated by NPM through its binding activity on nucleotides.

In conclusion. we found the induction of NPM in cisplatin-induced cytotoxicity in osteoblasts and suggested that NPM might play roles in DNA repair and/or damage response through some global regulation of the essential processes such as modulation of chromatin structure and control of

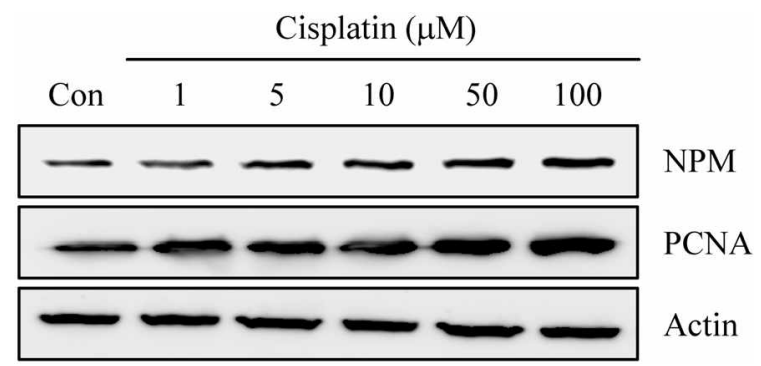

Figure 3. The effect of cisplatin on the protein expression levels of NPM and PCNA. Actin was used as an internal control. gene expression. Further studies such as gain-of-function and loss-of-function experiments will be required for elucidating the functional role of NPM and the precise mechanism by that NPM is regulated in normal cells in response to chemotherapeutic agents and these data would be helpful to evaluate the functional activity of cisplatin-related anticancer compounds or drugs in normal and cancer cells. ${ }^{8.9}$

\section{Experimental Section}

Cell culture. Mouse osteoblast MC3T3-EI cells were kindly provided by Dr. Lim (Department of Internal Medicine. Yonsei University College of Medicine, Seoul, Korea). MC 3T3-EI cells were maintained in alpha-modified essential medium (aMEM. Life Technologies. Inc.. MD) supplemented with $10 \%$ fetal bovine serum (FBS: HyClone Laboratories. UT). $100 \mathrm{U} / \mathrm{mL}$ of penicillin. and $100 \mathrm{mg} / \mathrm{mL}$ streptomycin with a change of medium every 3 days in humidified atmosphere of $5 \% \mathrm{CO}_{2}$ at $37{ }^{\circ} \mathrm{C}$

Cell proliferation assay. Cells were plated at a density of $4 \times 10^{2}$ cells in $\alpha$ MEM with 5\% FBS into 96-ivell plates and incubated for 1 day. The medium was changed with aMEM with $0.1 \%$ FBS and then next day. cells were incubated with cisplatin (1 to $100 \mu \mathrm{M}$ ). After l day or 4 days. cell proliferation was measured using Cell Counting Kit-8 (Dojindo Molecular Teclunologies. Inc.. ML) according to manufacturer's protocol. Significance was determined by Student's $t$-test and differences considered significant when $\mathrm{P}<0.05$.

Two-dimensional gel electrophoresis (2-DE). As previously described. 2-DE was carried out with modifications." Protein samples $(100 \mu \mathrm{g})$ were applied on Inmobiline Drystrip (pH 4-7, $18 \mathrm{~cm}$. Amersham Biosciences, Korea) and focused at total 57,000 Vhrs. The second-dimensional separation was performed on $12 \%$ polyacrylamide gels and 
then the gels were stained with silver staining kit (Amersham Biosciences) according to manufacturer's protocol.

Matrix-assisted laser desorption ionization-time of flight mass spectrometry (MALD-TOF MS). The excised protein spots from silver stained gel were cut into pieces and those gel pieces in $1.5 \mathrm{~mL}$ microtubes were destained with $120 \mu \mathrm{L}$ of $\mathrm{I}: \mathrm{I}$ mixture of $30 \mathrm{mM}$ potassium ferricyanide and $100 \mathrm{mM}$ sodium thiosulfate with vigorous shaking. Upon complete destaining. the destained gel pieces were washed three times with deionized water for $15 \mathrm{~min}$ with gentle shaking. once with $120 \mu \mathrm{L}$ of $50 \%$ acetonitrile $/ 25 \mathrm{mM}$ anmonium bicarbonate. $\mathrm{pH} 7.8$. for $10 \mathrm{~min}$ with shaking. and then inmersed with $50 \mu \mathrm{L}$ of acetonitrile for $5 \mathrm{~min}$. After removal of liquid, the gel pieces were dehydrated in a SpeedVac for $10 \mathrm{~min}$. The following steps were carried out as described previously. ${ }^{8}$

Western blot analysis. Protein expression levels were examined as described previously.

Acknowledgments. This work was supported by the Korea Science and Engineering Foundation (KOSEF) grant funded by the Korea government (MOST) No. M105260$20001-07 \mathrm{~N} 2602-00110$.

\section{References}

1. Young. D. R.: Virolainen. P.: Inoue. N.; Frassica. F. J. Chao, E. Y. J. Bone Miner Res. 1997. 12. 1874.

2. Ehrhart. N.: Eurell. J. A.: Tommasini. M.: Constable. P. D.: Johnson, A. L.; Feretti, A. Am. J. Iet. Res. 2002. 63. 703.

3. Choudhury. R. C.: Jagdale. M. B.: Misra. S. J. Chemother 2000. 12. 173 .

4. Wu. M. H. Chang J. H.; Yung. Y. M. Carcinogenesis 2002, 23,93 .

5. Weng. T. T.: Yung. B. Y. M. Biochem. Bioplns. Res Conmum. $2005.335,826$.

6. (a) Katz. A. T. Emiron. Mol M Haggen 1987. 10. 197. (b) Overbeck. T. L.: Knight. T. M.: Beck. D. T. Mutat. Res. 1996. 362.249.

7. (a) Yang C: Maiguel. D. A.: Carrier, F. Nucleic Acids Res. 2002. 30.2251. (b) Lee. S. Y.: Park. J. H.: Park. E. T.: Yun1. Y.: Kwont. J. Biochem. J. 2005, 388.7

8. Lee. E. J.: Jun, M.-J.: Sohn, Y. S. Bull. Korean Chem. Soc. 1998. 19. 1099.

9. Lee. E. J: Jun, M.-J.: Sohn, Y. S. Bull. Korean Chem. Soc 1999. 20. 1469 .

10. Lee. S.-U.: Kim. B. T.: Min. Y. K.: Kim. S. H. Cell Biol Int. 2006. 30.983 . 